\title{
Luís e Antônio Xavier de Jesus: trajetórias de africanos entre a Bahia e o Golfo do Benim, no século XIX
}

\author{
Elaine Santos Falheiros ${ }^{1}$
}

\begin{abstract}
Resumo: Este artigo tem por objetivo discutir alguns aspectos sobre as trajetórias de vida dos africanos Luís e Antônio Xavier de Jesus. Após anos vivendo na Bahia como escravo e uma vez conquistada a liberdade, Luís Xavier tornou-se um liberto rico e próspero. Em 1835, ele foi acusado de ter participado da revolta escrava, ocorrida em janeiro daquele ano. Ele foi preso e finalmente expulso do Brasil em novembro. Após partir para a África, Luís Xavier solicitou, insistentemente, o seu retorno à Bahia, para liquidar negócios deixados aos cuidados de seu ex-escravo, o também africano, Antônio Xavier de Jesus, mas nunca conseguiu regressar ao Brasil. Antônio Xavier, nomeado seu herdeiro universal, era também um dos receptadores de escravos africanos que Luís enviava ilegalmente da Costa da África, depois de 1835. Antônio herdou alguns dos bens do seu exsenhor, envolveu-se em conflitos e demandas judiciais ao longo da vida, o que também será objeto de análise do presente artigo.
\end{abstract}

Palavras-chave: Africanos libertos; Escravidão; Tráfico de escravos; Bahia; Costa da África.

\begin{abstract}
This article has the aim to discuss some aspects of the life trajectory of the Africans Luís and Antônio Xavier de Jesus. After years living in Bahia as a slave, and after he conquered his freedom, Luís Xavier became a rich and prosperous freedman. In 1835, Luís was one accused of participation in the Male uprising, happened in January of that year. He went to the jail, and finally expelled from Brazil in November of that year. After going to Africa, Luís Xavier petitioned several times for his return to Bahia, aiming at selling off his property, which he had left in under supervision by his African ex-slave by the name of Antonio Xavier de Jesus, but he could never return to Brazil. Antônio was Luís' universal heir and he was one of the slaves' receivers that Luís sent illegally from the African Coast, after 1835. Antônio received some of his ex-lord properties, got involved in conflicts and Judicial demands along his life, which will also be one analysis' object of this article.
\end{abstract}

Keywords: African freedmen; Slavery; Slave trade; Bahia; African Coast.

1 Mestra em História Social pela UFBA. E-mail: lanefalheiros@gmail.com . 


\section{Introdução}

Este artigo tem por objetivo apresentar e discutir aspectos relativos às trajetórias de vida de dois africanos que viveram na Bahia no século XIX, sobre os quais mais detalhes podem ser encontrados na dissertação de mestrado intitulada "Luís e Antônio Xavier de Jesus: mobilidade social de africanos na Bahia oitocentista". ${ }^{2}$ Um deles se chamava Luís Xavier de Jesus, nome católico atribuído ao africano de nação jeje, chegado à Bahia muito provavelmente na última década do século XVIII.

A contar do tempo médio transcorrido para a aquisição da alforria, que era de mais ou menos 10 anos, especulamos ter sido aquele o período em que Luís chegou em Salvador, tendo em vista que ele disse ter comprado sua liberdade em 1810, quando pagou $200 \$ 000$ (duzentos mil réis). Um ano depois, Luís recebeu da Coroa de Portugal, a patente de "capitão", talvez "capitão de entradas e assaltos", pessoa responsável por capturar escravos fugidos e aquilombados. ${ }^{3}$

Luís Xavier foi um africano que prosperou na Bahia após a sua emancipação. A partir de 1810, passou a viver como liberto em Salvador, investindo e desfrutando dos rendimentos de seus investimentos (escravos, imóveis e empréstimos a juros). Aparentemente viveu sem ter sido importunado quando demonstrou transitar entre os diversos grupos sociais da época. Durante o intervalo de tempo entre 1810 e 1835, Luís Xavier adquiriu pelo menos 11 imóveis todos localizados na atual região da Baixa dos Sapateiros e da Saúde (centro da cidade de Salvador). Também comprou, pelo menos, 28 escravos:

2 Elaine Falheiros, "Luís e Antônio Xavier de Jesus: mobilidade social de africanos na Bahia oitocentista", dissertação de mestrado, UFBA, 2013. Disponível em: $<$ https://repositorio.ufba.br/ri/bitstream/ri/17601/1/DISSERTA $\%$ C3\%87\%C3\%83O $\% 20 \mathrm{de} \% 20$ Elaine $\% 20$ Santos $\% 20$ Falheiros.pdf $>$.

3 Maria Inês Côrtes de Oliveira. O liberto: seu mundo e os outros. São Paulo: Corrupio 1988, p. 15. APEBA, Judiciária, Inventários, 09/3814/10, fl. 28. 
Quadro 1: escravos de Luís Xavier de Jesus

\begin{tabular}{|c|c|c|c|c|}
\hline NOME & NAÇÃO & OCUPAÇÃO & $\begin{array}{|ll|}\text { ANO } & \text { DE } \\
\text { CHEGADA } & \\
\end{array}$ & DESTINO \\
\hline Antônio & Nagô & - & 1828 & Antônio Xavier de Jesus \\
\hline Inácio & haussá & Pedreiro & 1841 & Vendido em 1855 \\
\hline Marcelino & haussá & oficial de pedreiro & 1830 & Vendido em 1855 \\
\hline Cassiano & haussá & Carpina & - & - \\
\hline João & Tapa & - & 1830 & - \\
\hline Joaquim & Nagô & Pedreiro & 1830 & Vendido em 1855 \\
\hline Dionísio & Nagô & - & - & - \\
\hline Pedro & Nagô & - & 1830 & Comprou sua alforria em 1855 \\
\hline Ventura & Nagô & - & 1830 & - \\
\hline Salvador & Nagô & \begin{tabular}{|ll}
$\begin{array}{l}\text { ocupação } \\
\text { saveiro }\end{array}$ & de \\
\end{tabular} & 1830 & Comprou sua alforria em 1850 \\
\hline Jorge & Nagô & Carpina & - & - \\
\hline Manoel & Nagô & serviço da roça & 1830 & - \\
\hline Agostinho & Nagô & - & - & - \\
\hline Geraldo & Nagô & - & - & - \\
\hline Prudência & cabinda & - & - & - \\
\hline Felisberta & Jeje & - & - & - \\
\hline Rita & Benim & - & - & - \\
\hline Claudina & Nagô & - & - & Vendida em 1855 \\
\hline Germana & crioula & serviço doméstico & - & Arrematada em 1855 \\
\hline Domingas & crioula & serviço doméstico & - & Arrematada \\
\hline Francisco & - & oficial de pedreiro & 1841 & Avaliado em 1855 \\
\hline Domingos & - & oficial de pedreiro & 1841 & Avaliado em 1855 \\
\hline Joaquina & - & serviço de ganho & - & Faleceu em 1854 \\
\hline Isabel & crioula & serviço de casa & - & Faleceu em 1854 \\
\hline Jacinta & Nagô & - & $24 / 03 / 1830$ & Fugiu em 1843 \\
\hline Josefa & Nagô & - & $24 / 03 / 1830$ & - \\
\hline Isabel & Nagô & serviço de casa & $24 / 03 / 1830$ & - \\
\hline Luis & - & - & - & - \\
\hline
\end{tabular}

FONTE: APEBA, Judiciária, Inventários, 09/3814/10.

Além dos rendimentos que recebia dos imóveis que alugava e dos jornais pagos por seus escravos de ganho, Luís ainda emprestava dinheiro a juros, muito provavelmente para membros da comunidade africana residentes em Salvador. Em 1826, ele renovou a dívida de Francisca do Sacramento, lhe emprestando mais de 120 mil réis. Francisca já havia lhe tomado 64 mil réis alguns anos antes. ${ }^{4}$

Luís Xavier ainda era proprietário de 2 armazéns de carne seca (onde eram comercializados 4 APEBA, Judiciária, LNT 220, fls. 118-118 v. 
outros produtos também), localizados na Praça do Comércio, em Salvador. Este local era justamente o ponto da cidade onde desembarcavam os escravos africanos recém-chegados, algum dos quais provavelmente Luís Xavier mandava trazer da África.

Luís teve como parceiros comerciais importantes traficantes da província da Bahia e da África, além de outros "pequenos parceiros", como africanos, alguns dos quais viajavam constantemente pelo Atlântico ao longo do século XIX, negociando escravos na África para serem levados a Salvador. Dentre os parceiros conhecidos, podemos citar João da Costa Júnior (proprietário de armação de baleia), Guilherme Martins do Nascimento (um crioulo retornado, viajante, que trabalhava com o traficante Joaquim de Almeida, na Costa da África) e José Maria de Freitas (morador na ilha de São Tomé, que tinha casa de negócio na corte do Rio de Janeiro). ${ }^{5}$

\section{Antônio Xavier de Jesus}

De todos os escravos que possuía, Luís Xavier nutria apreço especial pelo africano nagô, batizado com o nome de Antônio, em 1828, quando tinha aparentemente, 23 anos. Antônio certamente era mais uma das vítimas dos conflitos políticos e religiosos que se intensificaram na África na primeira metade do século XIX, mas que já vinham ocorrendo desde o final do século XVIII, dos quais, muito provavelmente Luís Xavier fora vítima também. ${ }^{6}$

Antônio ganhou destaque dentre os demais escravos, demonstrou inteligência para os negócios e foi favorecido por uma espécie de "hierarquia" da escravidão, quando seu senhor lhe delegou funções administrativas importantes. Antônio aprendeu a ler e a escrever, habilidades raras conquistadas por africanos na Bahia. Através de "grande ato de benevolência" de Luís Xavier, mas também estratégico Antônio foi liberto, alguns meses após a Rebelião Escrava de $1835 .{ }^{7}$

5 Pierre Verger cita João da Costa Junior e aponta documentos sobre a rede do tráfico que ele operava: Pierre Verger, Fluxo e refluxo do tráfico de escravos entre o Golfo de Benin e a Bahia de Todos os Santos dos séculos XVII ao $X I X .4^{a}$ ed. rev. Salvador: Corrupio, 1987, pp. 461-62 e 505, por exemplo. Para uma análise específica e recente, ver Falheiros, "Luís e Antônio Xavier de Jesus", cap. 2. Sobre Guilherme Martins do Nascimento, ver Lisa Earl Castillo, "The exodus of 1835: Àguda Life Stories and Social Networks". In: Tunde Babawale, Akin Alao and Tony Onwumah (orgs.). Pan-Africanism and the Integration of Continental Africa in Diaspora Africa (Lagos: Centre for Black and African Arts and Civilization, 2011), vol. 2, pp. 10-15 e sobre José Maria de Freitas, ver APEBA, Judiciária, Autos Cíveis, 41/1444/06.

6 João José Reis, Rebelião escrava no Brasil. São Paulo: Companhia das Letras, 2003. pp. 158-175.

7 Sobre a revolta escrava de 1835 na Bahia, ver: Reis, Rebelião escrava no Brasil. 
A revolta dos escravos foi um marco crucial na vida dos africanos que residiam em Salvador, principalmente por todo o clima de repressão que se instaurou na cidade após a rebelião. E Luís e Antônio Xavier de Jesus, como africanos, não passaram ao largo da repressão pós-levante. Foi neste contexto que eles tiveram suas trajetórias de vida completamente modificadas.

Luís Xavier não foi acusado formalmente, mas acabou sendo enquadrado na lei $\mathrm{n}^{\mathrm{o}}$ 9, de 13 de maio de 1835. Esta lei, dentre outros aspectos, autorizava o governo provincial a "expulsar do Brasil quaisquer africanos forros, de qualquer sexo, suspeito de promover a revolta daquele ano". ${ }^{8}$ Luís declarou-se inocente, mas a "suspeição" pairou sobre ele, e de acordo com o chefe de polícia Antônio Simões, em sua casa eram "frequentes as reuniões de africanos". Como salientou João Reis, estes encontros certamente não possuíam um caráter subversivo, mas deveriam ser festivos, com banquetes e divertimento para amigos e dependentes, uma prática muito comum entre africanos de prestígio de ambos os lados do Atlântico. ${ }^{9}$

$\mathrm{Na}$ época, de acordo com relatos das autoridades, Luís Xavier era um africano "abastado", que exerceria suposto "domínio" sobre os demais, e por este motivo deveria ser expulso do Brasil. Tal fato demonstra claramente a preocupação coletiva senhorial com o exemplo que os revoltosos poderiam dar aos demais escravos do país. O que Luís demonstrava naquele contexto era a possibilidade de ascensão social de um africano numa sociedade rigidamente hierarquizada e socialmente excludente.

Luís Xavier não acreditava que pudesse ser considerado um liberto revoltoso pelas autoridades da Bahia, afinal, conforme argumentou em um dos seus pedidos de retorno feitos posteriormente, já era um homem completamente adaptado aos valores e costumes daquela sociedade, não sendo capaz de se juntar com "selvagens" para promover uma revolta contra o sistema escravista. ${ }^{10}$

Meses após a revolta dos Malês, em novembro de 1835, Luís Xavier já estava preso, aguardando deportação para a Costa da África. Alguns dias depois embarcou certamente no patacho Maria Damiana fretado pelo governo brasileiro para que fossem levados entre 150 a 200 africanos de volta para a África, os quais seriam desembarcados em Ajudá, um ativo porto negreiro no Golfo do Benim. ${ }^{11}$ Caso tenha embarcado naquela ocasião, Luís deve ter sido recepcionado por Francisco

8 Reis, Rebelião escrava no Brasil, p. 498-503; Luciana da Cruz Brito, "Sob o rigor da lei: africanos e africanas na legislação baiana (1830-1841)", dissertação de mestrado, Unicamp, 2009, pp. 36-48.

9 Reis, Rebelião escrava no Brasil, pp. 481-482.

10 AN, GIFI, Cx. 5 B 207.

11 Lisa Earl Castillo. "The exodus of 1835: Àguda Life Stories and Social Networks”. In: Tunde Babawale, Akin Alao and Tony Onwumah, eds., Pan-Africanism and the Integration of Continental Africa in Diaspora Africa, vol. 2. 
Félix de Souza, o "Chachá de Uidá", um dos maiores traficantes de escravos da costa africana na primeira metade do século XIX.

Antes de partir para a Costa da África, Luís Xavier deixou com seu ex-escravo Antônio um embrulho, e lhes recomendou o máximo de cuidado e sigilo, lhe passando a responsabilidade e administração das lojas de carne seca. Os escravos e os imóveis ficariam sob a custódia de João da Costa Júnior, que conforme já mencionado, era um rico traficante de escravos e também proprietário de uma armação de baleia, localizada ao sul da província da Bahia. De acordo com relatos da época, nas terras de João da Costa eram realizados desembarques de escravos transportados ilegalmente, com a condescendência de algumas autoridades locais da Bahia. ${ }^{12}$

João da Costa Júnior exerceu, juntamente com outros negociantes negreiros da época, função na mesa administradora da Santa Casa de Misericórdia da Bahia. Foi preso em 1853, acusado de participar de um esquema de falsificação de papel moeda. João da Costa procurava diversificar suas atividades econômicas, minimizando assim os riscos inerentes ao comércio negreiro, principalmente diante da forte repressão inglesa, intensificada após a publicação do Equipment Act, em 1841. ${ }^{13}$

João da Costa Junior passou a gerir os bens de Luís Xavier (escravos e imóveis), sem nunca lhe prestar contas, por mais de 18 anos. Sobre isto, Luís disse que fora:

Constrangido a deixar seus negócios e administração de alguns bens de importância que adquirira com o seu trabalho à cargo de um procurador, o qual abusando da [sua] triste posição nunca lhe prestou contas, constituindo[-se] seu herdeiro em vida, de sorte que via-se reduzido ao mais triste estado de miséria nos últimos dias de sua vida, sem poder lançar mão daquilo que adquirira com o seu trabalho e indústria. ${ }^{14}$

E assim, João da Costa Junior arrecadou os alugueis dos imóveis e os jornais dos escravos em benefício próprio. Em 1850, vendeu alguns cativos de Luís para outras províncias do Brasil, quando do crescimento da demanda por escravos, durante o período de intensificação do tráfico

Lagos: Centre for Black and African Arts and Civilization, 2011, p 11.

12 Pierre Verger, Fluxo e refluxo, pp. 461-462.

13 Em 1853, um dos navios de João da Costa Junior foi apreendido no Rio de Janeiro. APEBA, Judiciária, Ação Ordinária, 33/1182/12, fl. 18.

14 AN, GIFI, Cx. 5 B 207. 
interprovincial. ${ }^{15}$

Enquanto João da Costa se desfazia de alguns de seus bens, Luís Xavier tentava regressar ao Brasil. Escrevendo diversas petições e pedidos de retorno às autoridades da província da Bahia e do Império. Estas certamente temiam o exemplo de ascensão social que Luís Xavier simbolicamente representava para a massa de libertos, que vivia na marginalidade e na pobreza. O fato é que seu retorno à Bahia nunca foi autorizado. As autoridades faziam um "jogo do empurra": enviava os documentos de uma instância para outra, recolhia pareceres, produziam dossiês, mas não decidiam definitivamente sobre os pedidos formulados pelo africano.

Enquanto permanecia aguardando a decisão sobre seus reiterados pedidos de retorno, Luís Xavier tentava obter um passaporte através de, José Herculano da Cunha, seu amigo, escrivão da Ouvidoria Geral do Crime de Salvador. Herculano também tentou ajudar Luís a regressar ao Brasil através de seu filho, que era então secretário do governador da província de Sergipe. ${ }^{16}$

Luís Xavier também solicitou ajuda a outro parceiro, José Maria de Freitas, mencionado anteriormente. De acordo com o próprio africano, José Maria iria até Lisboa para tentar obter sua naturalização portuguesa. Esta foi uma das estratégias utilizadas por Luís na tentativa de retornar ao Brasil, a fim de liquidar seus bens e voltar para a Costa da África, conforme prometia. Entretanto, ao que parece, Luís Xavier não conseguiu regressar ao Brasil, falecendo no final de 1854, em Ajudá, na Costa da África.

Assim que soube da morte de Luís Xavier, Antônio abriu o embrulho deixado aos seus cuidados por Luís em 1835. Nele, Antônio disse ter encontrado cartas de alforria de alguns escravos e também o testamento de Luís, ditado em 1835 na Bahia. Neste documento, Luís nomeou Antônio seu herdeiro universal. Por ocasião da descoberta do testamento pela polícia, Antônio foi preso e interrogado, sob a acusação de ter falsificado o testamento de Luís Xavier de Jesus. ${ }^{17}$

Dentre os autores da denúncia estavam João da Costa Júnior e Domingos José Cardoso, este Curador dos Órfãos e Ausentes de Salvador. Já vimos que João da Costa teria motivos suficientes

15Ricardo Tadeu Caíres Silva, “A participação da Bahia no tráfico interprovincial de escravos”, pp. 1-21. Trabalho apresentado no Encontro escravidão e liberdade no Brasil Meridional. Disponível em: $<$ http://www.escravidaoeliberdade.com.br/site/images/Textos3/ricardo\%20tadeu.pdf $>$. Acessado em: 25/05/2013; Richard Graham, "Nos tumbeiros mais uma vez? O comércio interprovincial de escravos no Brasil". Afro-Ásia, no 27 (2002), pp. 121-60. 16 Verger, Os libertos, p. 133.

17APEBA, Judiciária, Sequestro de bens, 41/1444/06. 
para acusar Antônio de ter falsificado o testamento. Entretanto, outra pessoa (uma autoridade) estava a acusá-lo. Para Domingos, era interessante que o testamento fosse considerado falso. Isto porque, como Luís não tinha herdeiros legais, sua herança ficaria retida nos cofres do Estado. Talvez a intenção fosse fazer com que os bens de Luís caíssem nas mãos de "interessados", ou seja, credores arranjados de última hora.

Após longa análise do testamento, os peritos judiciais concluíram que se tratava de um documento "antigo", e portanto, verdadeiro. Naquela altura, Antônio conseguiu herdar alguns bens que ainda restavam da herança de Luís Xavier, como os imóveis. Alguns dos escravos já tinham falecido e outros foram vendidos por João da Costa Junior. ${ }^{18}$ Comparando-se a quantidade de bens deixados por Luís Xavier em 1835 com os recebidos por Antônio, percebemos que houve uma redução no total de escravos (de 28 para 21), enquanto a quantidade de imóveis permaneceu inalterada. Entretanto, Antônio adquiriu mais 6 imóveis ao longo da vida, além dos 11 legados por Luís em 1855, totalizando 17 propriedades, em 1872.

No que se refere a aspectos da personalidade dos africanos, principalmente na relação com os escravos, percebemos que Luís Xavier tinha certa "compaixão" para com seus cativos: concedeu alforrias gratuitas e deixou seus bens para seu escravo de maior confiança, por exemplo. Por outro lado, Antônio Xavier demonstrou ser um senhor mais severo o que estimulava certamente a fuga de alguns escravos. Outros, considerados teimosos e desobedientes, furtavam pela cidade. O limite da negociação nas relações entre Antônio e seus escravos se deu em 1855, quando os cativos Francisco e Domingos foram trancados numa sala da casa do liberto. Antônio descobrira que esses escravos foram a uma botica para comprar veneno e "atentar contra a sua vida". Ou seja, as relações de Antônio Xavier com seus escravos eram tensas, marcadas por conflitos entre senhor e escravos. Estes fugiam e desobedeciam, chegando a atentar contra a vida do senhor. Por isso, eles eram castigados, inclusive com a venda para fora da província, certamente o pior dos castigos.

Antônio Xavier também envolveu-se em querelas com pessoas de outras camadas sociais de Salvador, como as livres e as libertas. Numa demanda judicial controversa movida por Constância da Rocha Pitta, Antônio foi acusado de ter sequestrado sua crioulinha, de nome Raimunda, como pagamento de uma dívida que, segundo ela, era falsa. ${ }^{19}$

18 APEBA, Judiciária, Autos Cíveis, 33/1182/12, fls. 84 v - 85 v e 164.

19 APEBA, Judiciária, Ações cíveis, 23/08/A/824/22. 
Em outro processo, movido pelo africano Manoel Grave, Antônio foi acusado de tentar reescravizá-lo. Manoel era filho adotivo de Emiliano Grave, um africano liberto de quem Antônio foi testamenteiro em 1856. Após a morte de Emiliano, Antônio propôs a Manoel, que fosse trabalhar em sua companhia, quando lhe prometeu "dar os lucros em compensação por seu trabalho". Se dizendo convencido pelas promessas de Antônio, Manoel aceitou a proposta, "aguardando as vantagens que lhe prometera, e assegurara pelos seus serviços”. Entretanto, após 13 anos, Antônio não havia cumprido sua palavra, e por este motivo, Manoel resolveu deixar sua companhia, segundo ele, altamente prejudicial. Para sua surpresa, Antônio se opôs veementemente, alegando "que o tinha comprado, e que, assim, pertencendo-lhe não devia, e nem podia dele apartar-se, sendo seu escravo!!!”. Ainda de acordo com Manoel Grave, Antônio passou a conspirar contra ele, “ameaçando-o com o cativeiro, e procurando convencê-lo do estado de escravidão". ${ }^{20}$

Quando ditou seu testamento, Emiliano Grave determinou a venda de um escravo chamado Manoel, para o pagamento de suas dívidas. Segundo Manoel, seu filho, o escravo Manoel foi entregue a Antônio Xavier, quando da morte de seu pai, que ficou de posse do cativo "até o tempo que lhe conveio". Após vender o escravo Manoel, Antônio teria se aproveitado da confusão com os nomes e da frágil condição social, em geral dos escravos e libertos, para tentar convencer as autoridades de que o escravo Manoel e Manoel Grave (o filho de Emiliano) eram a mesma pessoa.

Após anos de disputa na justiça, e com o falecimento de Antônio Xavier, em 1872, Manoel Grave desistiu do processo. É provável que pouco antes de morrer, Antônio, além de rezar para Nossa Senhora, de quem era devoto, tivesse ido buscar a proteção espiritual de sua comadre, Maria Madalena e da mãe-de-santo Marcelina da Silva, Obatossi, uma das fundadoras da Casa Branca, um dos mais tradicionais terreiros de candomblé da Bahia. Maria Madalena era comadre de Antônio, freguesa em sua loja e certamente uma mulher que buscou proteção espiritual para a família do africano, principalmente diante das tantas querelas e demandas judiciais nas quais ele se envolveu. Uma outra demanda na justiça que Antônio enfrentou foi contra o liberto africano Antão Pereira Teixeira, por causa da herança de uma afilhada de Felicidade Friandes, sua mulher. Antão tinha fama de feiticeiro e era dono de um candomblé na Cruz do Cosme. Em 1872, foi acusado de ter embebedado uma mulher parda, sua cliente, com o intuito de violentá-la sexualmente. Antão era também um homem violento, já tinha sido preso por tentar espancar sua mulher, e em 1875, acabou sendo expulso do Brasil ${ }^{21}$.

20APEBA, Judiciária, Libelo Cível, 26/919/01, fl. 22 v. Grifos originais.

21A disputa envolvendo Antônio Xavier e Antão Teixeira foi analisada por Reis, Domingos Sodré, um sacerdote africano: escravidão, liberdade e candomblé na Bahia do século XIX. São Paulo: Companhia das Letras, 2008, pp. 264-266. 


\section{Considerações finais}

As trajetórias de vida dos africanos no Brasil tem sido um tema de pesquisa bastante presente nos trabalhos que se inserem no campo da produção historiográfica da escravidão no país. Entretanto, o envolvimento de pequenos traficantes africanos, residentes no Bahia e na Costa da África, os quais estabeleciam redes fundamentais do comércio ilegal de escravos no século XIX, ainda é um tema pouco explorado.

A participação de Luís e Antônio Xavier de Jesus no tráfico não estava presente nas fontes, tendo sido necessário um aprofundamento das investigações históricas relativas aos africanos. Neste sentido, alguns fatos históricos foram importantes naquele processo. Primeiro, o fato de Luís ter enriquecido muito rapidamente na Bahia, algo incomum na época. Documentos encontrados durante a pesquisa também demonstram que havia um movimento de ida e vinda de escravos pelo Atlântico, alguns dos quais chegavam à Bahia para "aprender o ofício de pedreiro", certamente para construir na África casas com estilo arquitetônico do Brasil. Outro fato importante foi que Luís Xavier colecionou inimigos na costa africana, provavelmente seus concorrentes no negócio escravista. Em 1853, Luís disse ter sofrido um atentado, quando atearam fogo em sua casa no momento em que dormia. ${ }^{22}$

As redes do comércio movido por Luís, Antônio Xavier e outros parceiros serão exploradas durante a pesquisa de doutorado futura. Por ora, é importante destacar que a participação de libertos africanos no comércio ilegal é um tema relativamente novo no campo da historiografia. Por outro lado, os novos estudos da historiografia da escravidão no Brasil têm revelado a posse cada vez mais comum de escravos por libertos e também por outros escravos no seio das relações escravista no país. Tal aspecto tem sido definido como um tema "politicamente sensível", o qual tem levantado questões e inclusive conduzido a um debate que busca minimizar as lutas e conquistas das populações afro-brasileiras no Brasil nos últimos anos.

Acreditamos que, para além deste aspecto, um dos principais "ofícios" dos historiadores e historiadoras é o não julgamento precipitado sobre qualquer prática coletiva no contexto de uma sociedade do passado. Os libertos e escravos que possuíam cativos eram antes de mais nada seres humanos, portanto passíveis de ter condutas diversas e inesperadas. Além disso, a adequação às normas e valores de uma sociedade que tinha a escravidão como condição intrínseca de suas

22 APEBA, Judiciária, Autos Cíveis, 41/1444/06 (1855). 
relações sociais era além de previsível, desejada. Entretanto, mesmo em se tratando de prática comum, aquela ordem deveria ser questionada, contestada ou subvertida.

Acreditamos ser, no mínimo, injusto com a própria História, o estabelecimento de qualquer tipo de julgamento moral hoje, distante temporalmente dos fatos, sobre as condutas de escravos e libertos que tiveram que reinventar e reconstruir outras formas de viver naquela sociedade hierarquizada, excludente e adversa. Certamente para aqueles sujeitos, na maioria das vezes, "transformar a própria realidade" significava justamente se adaptar a ela, aproveitando as "brechas" do sistema para recriar outra forma possível de se sentir incluído socialmente.

Com o surgimento de novos sujeitos históricos no campo da historiografia, atualmente se faz importante conhecer mais sobre as histórias de vida das populações negras, subjugadas no passado. É necessário compreender como se operavam aquelas relações, considerando a própria dinâmica daquele tempo, e através dos resultados das investigações, estimular nos afro-brasileiros de hoje a percepção do papel desempenhado pelos povos negros no passado. Neste aspecto, torna-se relevante o debate e a luta contra o racismo e a desigualdade social, através da proposta e da criação de novos mecanismos capazes de incluir as populações afro-brasileiras, que ainda hoje encontram-se à margem da sociedade brasileira.

\section{Referências Bibliográficas}

ALENCASTRO, Luis Felipe de. O Trato dos Viventes: formação do Brasil no Atlântico Sul. São Paulo: Cia. das Letras, 2000.

ARAÚJO, Ubiratan Castro de. "1846: um ano na rota Bahia-Lagos. Negócios, negociantes e outros parceiros". Afro- Ásia, no 21/22 (1998-99), pp. 83-110.

BETHELL, Leslie. A abolição do comércio brasileiro de escravos: A Grã-Bretanha, o Brasil e a questão do comércio de escravos, 1807-1869. Brasília: Senado Federal, Conselho Editorial, 2002.

BRITO, Luciana da Cruz. "Sob o rigor da lei: africanos e africanas na legislação baiana (18301841)", dissertação de mestrado, Unicamp, 2009.

CASTILLO, Lisa Earl. "O terreiro do Alaketu e seus fundadores: história e genealogia familiar, 1807-1867”.Afro-Ásia, no 43 (2011), pp. 231-259.

. "The exodus of 1835: Àguda Life Stories and Social Networks". In: Tunde Babawale, Akin Alao and Tony Onwumah (orgs.). Pan-Africanism and the Integration of Continental Africa in Diaspora Africa (Lagos: Centre for Black and African Arts and Civilization, 2011), vol. 2, pp.27-51.

; e PARÉS, Luis Nicolau. "Marcelina da Silva e seu mundo: Novos dados para uma historiografia do Candomblé Ketu". Afro-Ásia, no 36 (2007), pp. 111-50.

CHALHOUB, Sidney. A força da escravidão: ilegalidade e costume no Brasil oitocentista. São Paulo: Companhia das Letras, 2012. 
CONRAD, Robert. Tumbeiros: o tráfico escravista para o Brasil. São Paulo: Brasiliense, 1985.

CUNHA, Manuela Carneiro da. Negros estrangeiros. Os escravos libertos e sua volta à África. São Paulo: Brasiliense, 1985.

CUNHA, Mariano Carneiro da. Da senzala ao sobrado: arquitetura brasileira na Nigéria e na República Popular do Benim. São Paulo: Nobel; Editora da Universidade de São Paulo, 1985.

DOMINGUES, Petrônio. "Lino Guedes: de filho de ex-escravo à 'elite de cor'”. Afro - Ásia, n 41 (2010), pp. 133-166.

ELTIS, David; BEHRENDT, Stephen D.; RICHARDSON, David. "A participação dos países da Europa e das Américas no tráfico transatlântico de escravos: novas evidências". Afro - Ásia, $\mathrm{n}^{\mathrm{o}} 24$ (2000), pp. 9-50.

FARIAS Juliana Barreto; SOARES, Carlos Eugênio Líbano e GOMES, Flávio dos Santos. No labirinto das nações: Africanos e identidades no Rio de Janeiro, século XIX, Rio de Janeiro: Arquivo Nacional, 2005.

FLORENTINO, Manolo. Em Costas Negras: uma história do tráfico entre a África e o Rio de Janeiro (séculos XVIII e XIX). São Paulo: Companhia das Letras, 1997.

GOULART, Mauricio. A escravidão africana no Brasil: das origens à extinção do tráfico. São Paulo: Alfa-Ômega, 1975.

GRAHAM, Richard. "Nos tumbeiros mais uma vez? O comércio interprovincial de escravos no Brasil". Afro - Ásia, no 27 (2002), pp. 121-60.

GUINZBURG, Carlo. "O nome e o como". In: GUINZBURG, C. etalli. A micro-história e outros ensaios. Lisboa: Difel, 1991, pp. 169-178.

GURAN, Milton. "Da bricolagem da memória à construção da própria imagem entre os agudás do Benim". Afro-Ásia, no 28 (2002), pp. 45-76.

LAW, Robin. "A comunidade brasileira de Uidá e os últimos anos do tráfico atlântico de escravos, 1850-66". Afro - Ásia, no 27 (2002), pp. 41-77.

; MANN, Kristin. "West Africa in the Atlantic Community: The case of the Slave Coast". The William and Mary Quarterly, $3^{\text {rd }}$ Ser., vol. 56, $\mathrm{n}^{\circ} 2$, (1999), pp. 307-334.

LEVI, Giovanni. "Sobre a micro-história". In: BURKE, Peter (org.), A escrita da história: novas perspectivas. São Paulo: Ed. UNESP, 1992, pp. 133-161.

LOVEJOY, Paul. A escravidão na África: uma história de suas transformações. Rio de Janeiro: Civilização Brasileira, 2002.

. "Identidade e a miragem da etnicidade: a jornada de Mahommah Gardo Baquaqua para as Américas". Afro-Ásia, no 27 (2002), pp. 9-39.

MATTOSO, Kátia M. de Queirós. Testamentos de escravos libertos na Bahia no século XIX: uma fonte para o estudo de mentalidades. Salvador: Centro de Estudos Baianos, 1979.

. Família e sociedade na Bahia no século XIX. Salvador: Corrupio, 1988.

. Ser escravo no Brasil. São Paulo: Brasiliense, 1982.

NASCIMENTO, Anna Amélia Vieira. Dez freguesias da Cidade do Salvador; Aspectos Sociais e Urbanos do Século XIX. Salvador: FCEBa. /EGBa., 1986.

OLIVEIRA, Maria Inês Côrtes. O liberto: seu mundo e os outros. São Paulo: Corrupio 1988.

. "Quem eram os negros da Guiné? A origem dos africanos na Bahia". Afro-Ásia, no 1920 (1997), pp.37-73.

"Viver e morrer no meio dos seus. Nações e comunidades africanas na Bahia do século XIX”. Revista da USP, n²8 (1995/6), pp. 175-193.

REIS, João José. Rebelião escrava no Brasil: a história do levante dos Malês em 1835. São Paulo: Companhia das Letras, 2003.

"De escravo a (rico) liberto: a trajetória de Manoel Joaquim Ricardo". Texto inédito. 
Domingos Sodré, um sacerdote africano: escravidão, liberdade e candomblé na Bahia do século XIX. São Paulo: Companhia das Letras, 2008.

; GOMES, Flávio dos S. e CARVALHO, Marcus J. M.O alufá Rufino: tráfico, escravidão e liberdade no Atlântico Negro (c.1822 - c.1853). São Paulo, Companhia das Letras, 2010.

; SILVA, Eduardo. Negociação e conflito: a resistência negra no Brasil escravista. São Paulo: Companhia das Letras, 1989.

RODRIGUES, Jaime. De Costa a Costa: escravos, marinheiros e intermediários do tráfico negreiro de Angola para o Rio de Janeiro (1780-1860). São Paulo: Companhia das Letras, 2005.

O Infame Comércio: propostas e experiências no final do tráfico de africanos para o Brasil (1800-1850). Campinas, SP: Editora da Unicamp/CECULT, 2000.

ROSS, David. "The career of Domingo Martinez in the Bight of Benin, 1832-1864". The Journal of African History, vol.6, n ${ }^{\circ} 1$ (1965), pp.79-90.

SCHWARTZ, Stuart B. Segredos Internos: Engenhos e escravos na sociedade colonial: 1500-1835. São Paulo: Companhia das Letras, 1999.

SILVA JR., Carlos. "Tráfico, escravidão e comércio em Salvador do século XVIII: a vida de Francisco Gonçalves Dantas (1699-1738)". In REIS, João José e AZEVEDO, Elciene (orgs.). Escravidão e suas sombras. Salvador: EDUFBA, 2012, pp. 143-185.

SILVA, Ricardo Tadeu Caíres. "A participação da Bahia no tráfico interprovincial de escravos (1851-1881)", pp. 1-21. Artigo publicado no $3^{\circ}$ Encontro escravidão e liberdade no Brasil Meridional.

Disponível em:

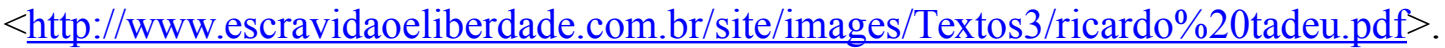
Acessado em: 25/05/2013.

SOUZA, Mônica Lima e. "Entre margens: o retorno à África de libertos no Brasil, 1830-1870", tese de doutorado, Universidade Federal Fluminense, 2008.

TAVARES, Luís H. Dias. Comércio proibido de escravos. São Paulo: Ática/CNPq. 1988.

TURNER, J. Michael. "Escravos brasileiros no Daomé". Afro-Ásia, no 10-11 (1970), pp. 1-19.

VERGER, Pierre. Fluxo e refluxo do tráfico de escravos entre o Golfo de Benin e a Bahia de Todos os Santos dos séculos XVII ao XIX. $4^{\mathrm{a}}$ ed. rev. Salvador: Corrupio, 1987.

. Os libertos: sete caminhos na liberdade de escravos da Bahia no século XIX. Salvador: Corrupio, 1992.

XIMENES, Cristiana Ferreira Lyrio. "Joaquim Pereira Marinho: perfil de um contrabandista de escravos na Bahia, 1828, 1887’. Dissertação de Mestrado. Salvador: UFBA, 1999.

\section{Recebido em 12/05/16 - Aprovado em 05/07/16}

